\title{
Formation of Ethnic Identity of School children By Means Of Museum Pedagogics
}

\author{
Elmira M. Bainiyazova ${ }^{1}$, Iskander E. Yarmakeev², Rimma M. Akhmadullina ${ }^{3}$, Nelly R. Valiakhmetova*4, \\ Erbol T. Bekish ${ }^{5}$ \\ ${ }^{1,2,3,4}$ Kazan Federal University, Leo Tolstoy Institute of Philology and Intercultural Communication; ${ }^{5}$ Korkyt Ata \\ Kyzylorda State University, The Department of Social-Humanitarian Disciplines, The Department of Practical \\ English; \\ *Email: nellyv1975@mail.ru, Tel.89178892268.
}

Received: 21st October 2017 Accepted: 16th November 2017, Published: 31st December 2017

\begin{abstract}
The article is devoted to the urgent problem of modern society - the need for the formation of ethnic person identity with the goal of preserving the uniqueness of the national and cultural space in the current globalization processes. The authors emphasize the relevance of this problem for the Republic of Tatarstan, as a multicultural region of the Russian Federation. The solution of this task must be carried out already at the schooling stage. In this regard, the article actualizes the problem of finding the most effective means of forming the ethnic identity of pupils of comprehensive secondary schools. Theoretical provisions, concerning the essence of the concept "ethnic identity", the substantive stages of its development, as the characteristic of personality, are described in the work.

In the opinion of the authors, museum pedagogy, which is one of the modern branches of pedagogical science, has a significant potential for the formation of ethnic identity. The work focuses on the unique role of the museum in solving the problem under study. The authors of the article propose a model for the formation of ethnic identity of school children, using museum pedagogy, and experimentally prove its effectiveness. The work describes the diagnostic methods and dynamics of the results at the control and forming stages of the experiment.

The article can be recommended to teachers and museum teachers, for solving the problems of formation of national and ethnic self-awareness in students.
\end{abstract}

Keywords: Ethnic Identity, Formation, Secondary School Student, Means of Museum Pedagogy, Model.

\section{Introduction}

The processes of economic, information, sociocultural globalization, existing in the modern world, on the one hand, promote the unification of people of different ethnic groups in joint activities on development the production, on expanding the boundaries of cultural space; on the other hand, there is a serious danger of the loss of historically formed diversity and distinctness of ethnic cultures, and the uniqueness of the own culture of personality. The ongoing socio-cultural processes actualized the problems of identity, concerned with the desire of a person to learn, understand himself and determine the own place in society. The multinational composition of the Russian Federation, the migration processes, intensified in society, put a premium on the problem of the ethnic identity formation. This issue becomes especially urgent for Tatarstan, which is a polyethnic region of the Russian Federation. The representatives of 173 nationalities and ethnic groups live here. In these conditions, positive ethnic identity is the key to development of prosperous inter-ethnic relations. For this reason, the formation of ethnic identity among the younger generations is the main task of modern education. So, in the Strategy of Education Development in the Russian Federation for the period until 2025, the special attention is drawn on the need to educate a Russian citizen, who combines love for a large and a small homeland, national and ethnic identity, respect for culture, and the traditions of people, who live side by side [1].Federal State Educational Standard of Secondary (Complete) General Education is intended to ensure the preservation and development of cultural diversity and linguistic heritage of the Russian people, the realization of the right to learn native language, the acquisition of spiritual values and the culture of multinational people of Russia [2].

The problem of the formation of students' ethnic identity has been the subject of many scientific studies, but the issues of technological support of this process, effective pedagogical means are still insufficiently developed. This circumstance determined the direction of our study.

Considerable potential for the formation of ethnic identity of schoolchildren, in our opinion, contains the means of museum pedagogy.

The purpose of this study is to identify and experimentally substantiate the effectiveness of the model of ethnic identity formation in schoolchildren through museum pedagogy. 


\section{Materials and Methods}

The methodological basis of our research was the culturological approach in education and upbringing [3]; the ideas of ethnic identity formation [4], [5], [6], [7], [8], [9]; the correspondence of the contents of educational material of ethnicity and the mental characteristics of students [10]; pedagogical support of schoolchildren in the conditions of integrated educational environment [11]; researches on the development of child activity in the museum environment [12].

Modern domestic ethnopsychology considers ethnic identity as a result of cognitive-emotional process of self-perception as a representative of ethnos, a certain degree of self-identification with it and separation from other ethnic groups [7]. In accordance with the concept of J. Piaget, ethnic identity can be realized at the age of 10-11, when the child notes the uniqueness of history, the specificity of traditional domestic culture, as the features of different nations [13].

Analyzing the model of stadial development of teenager's ethnic identity, developed by J. Finney [14], we come to the conclusion, that the forming influence of cultural, educational means should be realized, first of all, at the stage, characterized by the search for ethnic identity, the desire for its study, the understanding of its personal significance. This is facilitated by reading, talks, visits to museums, active participation in cultural events, etc. The success of the transition to the final stages of the formation of ethnic identity, characterized by a stable attachment to ethnic culture, the desire for its further research, depends on the effectiveness of chosen means.

Among the significant factors, affecting the formation of ethnic identity, an important role belongs to the accessibility of samples of ethnic culture. The cultural and educational potential of museum pedagogy contributes to the realization of this factor, in our opinion.

Museum pedagogy is one of the directions of pedagogical science, and is defined as an interdisciplinary field of scientific knowledge, formed at the intersection of pedagogy, psychology, and museology, and specific practical activity, created on this basis and focused on the transfer of cultural experience [15]. It is also considered as a separate science about the processes of changing the internal image of person, by specific methods and means, which are provided by various forms of museum activity [12]. The educational environment of the museum creates the conditions for the development of students' interest in the history of their people, national art, emotional attraction to ethnic culture, customs, traditions. The unique role of the museum is that it has the ability to influence the intellectual, emotional and moral spheres simultaneously; to give the opportunity of gaining the experience of direct personal contact with history and culture. This feature contributes to the effective formation of cognitive, affective and behavioral structural components of ethnic identity.
In the context of our research, the following issues are referred to the means of museum pedagogy: modern models of teaching in the museum, integrated educational museum programs, methods, forms and technologies of museum pedagogy.

The research methods were the analysis of theoretical sources, systematization, interviewing, pedagogical modeling, testing, pedagogical experiment.

The study involved schoolchildren,11-12 year-old (the sample consisted of 70 participants), all representatives of ethnic Russians, as well as five teachers, who teach humanitarian subjects (literature, social studies, history). The study has been taken place during six months on the basis of general education schools in Kazan.

At the first stage of the study -indicative - the method of interviewing was used. It showed that teachers do not pay much attention to the ethnicity of the heroes and participants of the events, or authors of art works, during the training, using the museum educational environment. This is explained by the fact, that Russia is a multiethnic country and an emphasis on ethnic roots can cause a negative reaction among children from other ethnic groups. And only one of the respondents, organizing excursions to museums, sets the goal of forming national self-consciousness, ethnic and cultural identity of schoolchildren. Further, the "Methodology for assessing the positivity and uncertainty of ethnic identity" (A.N. Tatarko, N.M. Lebedeva) [16], consisting of two scales, was applied to determine the degree of expression of ethnic identity of students. The first scale evaluates the degree of positivity of ethnic identity, that is, the emotional coloring of ethnic identity; the second estimates the degree of uncertainty of the respondent's ethnic identity, that is, how clearly the respondent feels himself to be a representative of his nation. When processing the data, the average values for each scale were calculated, and the test indicators, corresponding to low, reduced, average, increased and high degrees of emotional color and uncertainty of ethnic identity were determined.

The results of primary diagnosis of positivity and uncertainty of ethnic identity showed, that the majority of schoolchildren (52\% of the sample) had an average degree of awareness of their belonging to the ethnic group. Also, the majority of students (74\% of the sample) had the average level of emotional attitude to their ethnicity.

Further, in accordance with the stated goal, at the forming stage of pedagogical experiment, we created and tested a model for the development of students' ethnic identity, by means of museum pedagogy.

As a result of theoretical analysis, the following principles for model construction were defined:

1. Principle of integration. Implies the integration of: - The content of definitive training and educational activities;

- learning and extracurricular (research, creative activity of schoolchildren); 
- intersubject integration, based on the idea of the impossibility of art works perception from the standpoint of only one school discipline;

- Traditional and innovative methods of museum training with children;

- Professional study of art and pedagogical practice in the activities of the museum teacher and guide;

- Activity of the subject teacher and museum teacher at the content and technological levels.

2. The axiological principle. In the process of perception the work of art, the emphasis lies not on knowledge, but on the empathy with the creative idea of its author, the formation of the experience of a value feeling the significance of a cultural historical event or artifact.

3. Humanization, based on the personal-activity approach. In the context of our research, it means the creation of conditions for students, to be included in various types of museum and educational activities, which will allow them to fully reveal their personal potential.

4. Programmability. The model for the formation of ethnic identity is based on a specially developed museum and pedagogical program, which integrates the programs of the activities of museum and school programs of upbringing and education.

The model itself reflects an organized pedagogical process, the structure of which includes the following components:

1. Objective. It includes the formation of ethnic identity of schoolchildren through museum pedagogy by solving the following problems:

- Understanding, awareness and acceptance by schoolchildren of themselves as representatives of a certain ethnos, familiarization with its culture, norms and values;

- Formation of a sense of belonging to one's ethnic group, accompanied by positive emotions;

- Respect for the cultural and historical heritage, traditions and history of nation.
2. Contensive. The integrated museum and educational program "Me and my people" was its base. The program was implemented on the basis of art, national museums and house museums in Kazan. 3. Operational and technological. Its structure is based on the combination of traditional and innovative methods, technologies and forms of museum training. Traditional ones are public lectures, excursions, master classes, children's exhibitions. Innovative methods include: animated plans and schemes, video panoramas, search systems, interactive classes, based on contacts with the exhibit item.

4. Resulting-evaluative component implies an assessment of the effectiveness of the process of forming the ethnic identity of school children, through the use of museum pedagogy on the basis of the following criteria: clarity of self-perception as a representative of a certain ethnos and emotional coloring of ethnic identity.

At the control stage of the experiment, students were tested again, using the technique of A.N.Tatarko, N.M.Lebedeva.

\section{Results}

Retesting of schoolchildren after the introduction of created model showed a positive dynamics of the development of their ethnic identity. Comparative results of changes in the number of students with different degrees of uncertainty and positivity of ethnic identity are shown in Figure 1 and Figure 2.

The data in Figure 1 showed, that the number of students at the control stage of the experiment was increased compared to the summative stage: with a low degree of ethnic uncertainty by $2 \%$, with a reduced degree - by $1 \%$, and with average degree - by $6 \%$. The high and increased degrees of uncertainty, on the contrary, were decreased by $6 \%$ and $3 \%$, respectively.

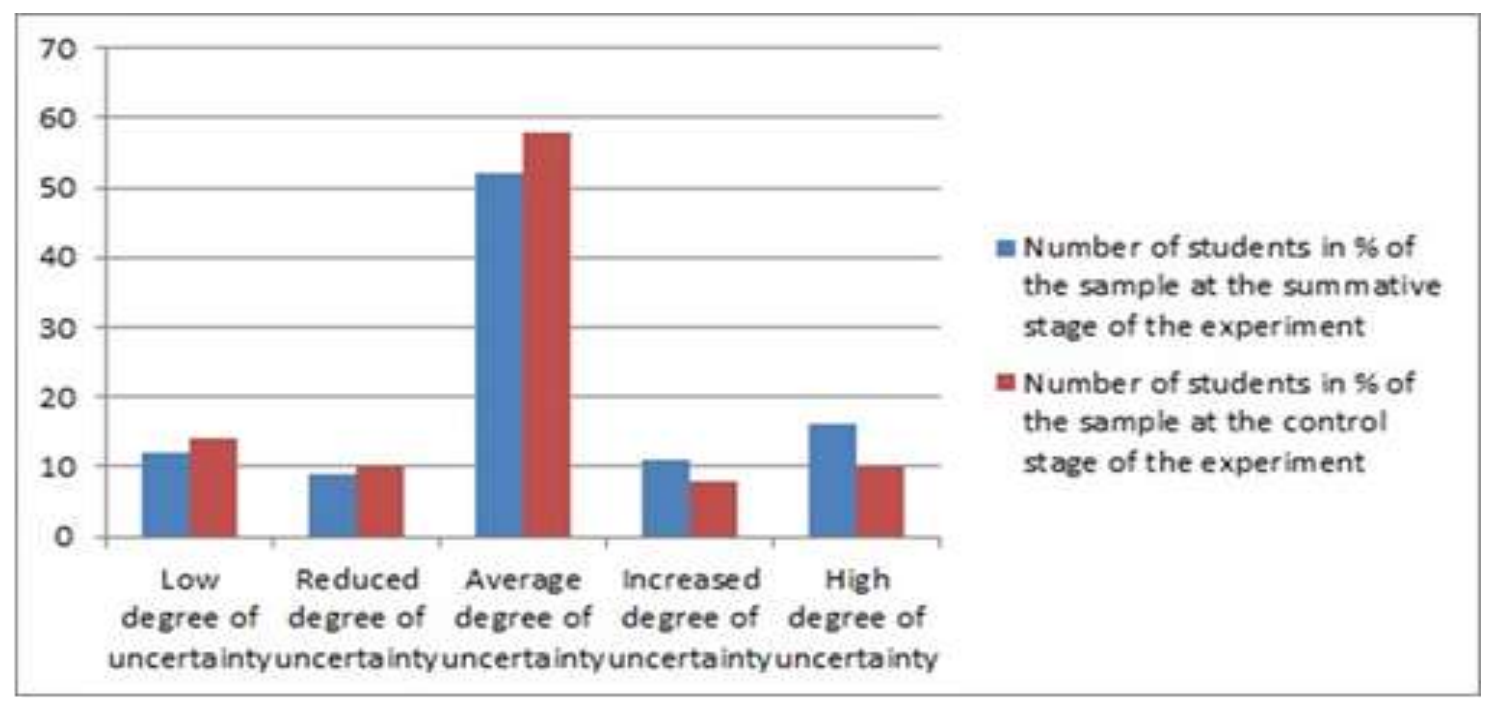


Figure 1. The Number of Students with Different Degrees of Uncertainty of Ethnic Identity, at the Summative and Control Stages of the Experiment

The data in Figure 2 showed an increase in the number of students with a high degree of positivity of ethnic identity by $3 \%$, and with an increased degree - also by $3 \%$. The number of students with a low degree of positivity decreased by $4 \%$, with reduced degree - by $1 \%$, and with average degree - by $1 \%$.

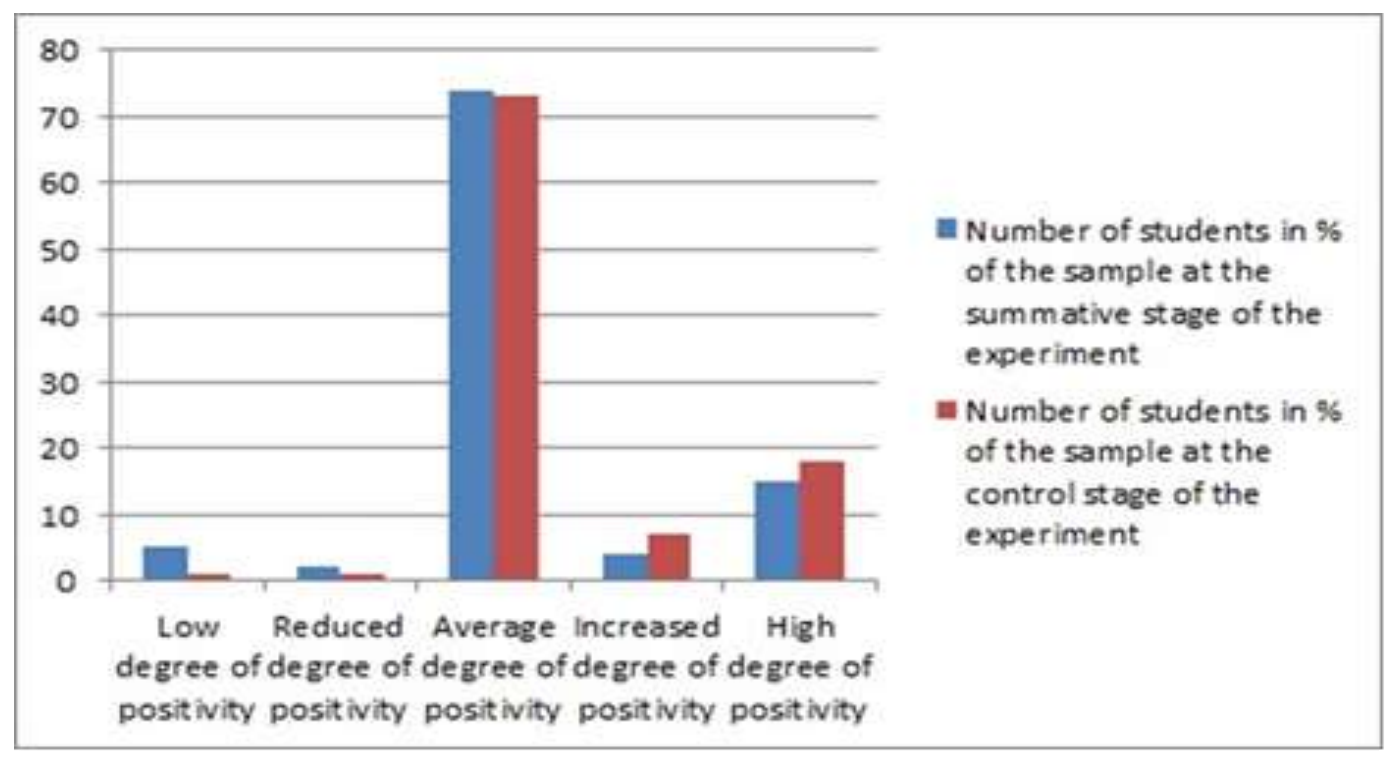

Figure 2. The Number of Students with Different Degrees of Positivity of Ethnic Identity, at the Summative and Control Stages of the Experiment

\begin{abstract}
Discussion
On the one hand, the problem of ethnic identity formation in younger generation is widely represented in modern scientific researches, in particular, in the works of Phinney J.S. [4], Stefanenko T.G. [7], etc. We agree with the authors, that a key role in this process is played by cultural and educational space; purposeful pedagogical support and active character of students' activity. On the other hand, the issues of effective pedagogical means of forming ethnic identity are not sufficiently developed. The results of our study made it possible to state, that the museum's pedagogy, capable of forming a stable positive ethnic identity, as well as patriotism, adequate self-esteem, self-respect, have a significant potential in solving the stated problem.
\end{abstract}

\section{Conclusions}

The formation of ethnic identity of the personality is relevant in connection with the need to preserve the national and cultural identity of modern Russia, in the context of globalization and strengthening of migration processes. Integration of school and museum educational potentials can serve as an effective tool for this process. The results of experimental work have proved the effectiveness of the developed model and the program for the formation of ethnic identity of schoolchildren, using the means of museum pedagogy. These data can be used by school teachers and museum teachers to organize joint cultural and educational programs.

\section{Acknowledgement}

The work is performed according to the Russian Government Program of Competitive Growth of Kazan Federal University

\section{References}

1. Strategy for the development of education in the Russian Federation for the period until 2025. URL: https://rg.ru/2015/06/08/vospitanie-dok.html. (Access date: March 4, 2017).

2. Federal state educational standard of secondary general education. URL: http: //www.xn-80achddrlnpe7bi.xn--p1ai/index.php/fgosob.html (Access date: March 4, 2017).

3. Bondarevskaya, E.V., Kulnevich, S.V. (1999). Pedagogy: personality in humanistic theories and educationasystems. Rostov-on-Don.: Uchitel. 560p. 4.Phinney, J. S., Horenczyk, G., Liebkind, K., Vedder, P. (2001). Ethnic Identity, Immigration, and Well-Being: An Interactional Perspective. Journal of Social Issues.Vol.57 (3). Pp. 493-510.

5.Brubaker, R., Cooper, F. (2002).Beyond Identity.Theory of Society. Dordrecht. Vol. 29, № 1. Pp. 1-47.

6.Fearon, J. D. (2003).Ethnic and Cultural Diversity by Country.Journal of Economic Growth.№ 8. Pp. 195-222.

7.Stefanenko, T.G. (2013).Ethnopsychology: practical course. Moscow: Aspect-Press. 224p. 
8.Salpykova, I., Akhmadullina, R., Valiakhmetova, N., \& Valiahmetova, A. (2016).Formation of Tolerance of Schoolchildren in the Conditions of Cooperative Learning (Regional Aspect). In Edulearn 2016: Proceedings of the 8th International Conference on Education and New Learning Technologies. pp. 7822-7829. Barcelona, Spain. doi: 10.21125/edulearn.2016.0715.

9.Valiakhmetova, N.R.,Akhmadullina, R.M.,Pimenova, T.S. (2017).Ethno-pedagogy as a means of ethnic identity formation of pre-service teachers in Russia.SOCIOINT 2017.Proceedings of the 4th International conference on education, social sciences and humanities. DUBAI (UAE).

10.Abdrafikova, A.R., Akhmadullina, R.M., Singatullova, A.A. (2014). Specific features of teaching English language in multicultural space (on the example of the religious educational institutions of the Republic of Tatarstan).Life Science Journal, 11(8), pp.542-544. doi:10.7537/marslsj110814.75.

11.Yarmakeev, I. E., Akhmadullina, R. M., Valiahmetova, N. R., Sjunina, A.S. (2016).Pedagogical support of gifted learners in the context of network interaction school-university (regional aspect).Turkish online journal of design art and communication.Vol.6, pp.2433-2439.doi no: 10.7456/1060NVSE/041.

12. Stolyarov, B.A. (2013).Pedagogical aspects of the museum educational activity. St. Petersburg: SRM. 310p.

13.Piaget, J. \& A. Weil (1951).The development in children of the idea of the Homeland and of relations with other countries, International Social Science Bulletin 3, pp. 561-578.

14.Jean S. Phinney (1990). Ethnic identity in adolescents and adults: Review of research, Psychological Bulletin, Vol. 108(3), Nov, pp. 499514.

15.National Pedagogical Encyclopedia. URL: http://didacts.ru/termin/muzeinajapedagogika.html.(Access date: March 24, 2017). 16. Tatarko A.N.,Lebedeva N.M. (2011).Methods of ethnic and cross-cultural psychology. Moscow: Publishing house of Higher School of Economics, 22 p. 